\title{
Analgesic, Sedative and Hemodynamic Effects of Dexmedetomidine Following Major Abdominal Surgeries: A Randomized, Double- Blinded Comparative Study with Morphine
}

\author{
Khaled Taha \\ Assistant Professor, Anesthesia Department, Faculty of Medicine, \\ Ain Shams University
}

\begin{abstract}
This was a randomized double-blinded study; in which 60 ASAI-II adult patients scheduled for major abdominal surgeries (colostomy, radical cystectomy, major gynecological surgery, and abdominal vascular surgery) were received standard general anesthesia. Twenty minutes before the anticipated end of surgery, patients were randomized into two equal groups: dexmedetomidine group (group D) and morphine group (group $\mathrm{M}$ ). Group D received dexmedetomidine IV infusion $4 \mu \mathrm{g} / \mathrm{kg} / \mathrm{h}$ for 15 minutes $(1 \mu \mathrm{g} / \mathrm{Kg})$ followed by $0.4 \mu \mathrm{g} / \mathrm{kg} / \mathrm{h}$ for $3 \mathrm{~h}$. Group M received morphine sulfate IV $(0.07 \mathrm{mg} / \mathrm{kg})$. All patients were given a morphine patient controlled analgesia (PCA) pump in the post anesthesia care unit (PACU), delivering IV morphine $2 \mathrm{mg}$ with a lockout time of 5 minutes if pain score assessed through visual analog scale (VAS) was more than 5 at any given 5-min assessment. During the PACU recovery period, morphine consumption; pain and sedation scores; hemodynamic variables (heart rate, mean arterial blood pressure, oxygen saturation and respiratory rate); and postoperative nausea, retching and vomiting (PONV) were recorded every $30 \mathrm{~min}$ for $3 \mathrm{~h}$ (study period) by a member of staff blinded to the treatment. The study demonstrated that the use of dexmedetomidine led to significant decrease in the total amount of morphine consumed throughout the entire PACU recovery period $(\mathrm{P}<0.05)$. This was associated with reasonable pain and sedation scores; significant slowing in heart rate $(\mathrm{P}<0.05)$; significant decrease in mean arterial pressure $(\mathrm{P}<0.05)$; less incidence of $\mathrm{PONV}(\mathrm{P}<0.05)$; without any significant changes in oxygen saturation $(\mathrm{P}>0.05)$ or respiratory rate $(\mathrm{P}>0.05)$. In conclusion, dexmedetomidine exhibited both analgesic and sedative properties. The associated cardiovascular protective pharmacological profile and the lack of respiratory depression made it potentially extremely interesting for postoperative analgesia after major abdominal surgeries.
\end{abstract}

\section{Introduction:}

Dexmedetomidine is a potent alpha-2 adrenoceptor agonist with an alpha-2 to alpha-ratio more than 7times that of clonidine $^{(1)}$. Because of its potency, it can be safely administered as an infusion (not as a bolus). Dexmedetomidine has analgesic and sedative properties ${ }^{(2,3)}$. Its use is not associated with respiratory depression despite profound levels of sedation ${ }^{(3)}$. Because of analgesia sparing, sedation and lack of respiratory depression, dexmedetomidine may prove useful in the postoperative period for patients having major surgical procedures that are associated with significant pain.

\section{Aim of the Work}

The aim of this study was to assess the analgesic, sedative and hemodynamic effects of dexmedetomidine and to compare it to morphine in early postoperative period following major abdominal surgeries.

Patients and Methods

The study was approved by the hospital ethical committee. A written informed consent was obtained from all patients to participate in this study. Sixty adult patients ASA physical status class I and II scheduled to undergo major abdominal surgeries under general anesthesia were enrolled in the study. Exclusion criteria 
included patients with body weight greater than $100 \mathrm{~kg}$, patients receiving any alpha-2 agonists or antagonists or patients on chronic use of opioids in the last 4 weeks of the study.

On the eve of the surgery, patients were instructed on the proper use of the visual analog scale for assessing pain and sedation (10-point scale) and the patientcontrolled analgesia (PCA) apparatus. An independent observer administered the visual analog scales in the postoperative period.

The general anesthesia regimen consisted of premedication with midazolam $3 \mathrm{mg}$ IV given prior to surgery. Induction was with fentanyl $1.5 \mu \mathrm{g} / \mathrm{kg}$ IV and propofol $2 \mathrm{mg} / \mathrm{kg}$ IV. Atracurium $0.6 \mathrm{mg} / \mathrm{kg}$ was used to facilitate endotracheal intubation. Anesthesia was maintained with $66 \%$ nitrous oxide in oxygen and isoflurane to achieve an end-tidal isoflurane concentration of about $1 \%$. Intraoperative analgesia was provided by increments of fentanyl. Ventilation was controlled mechanically and adjusted to maintain end-tidal carbon dioxide at $38 \mathrm{~mm} \mathrm{Hg}$ throughout the surgery. Atracurium was supplemented during general anesthesia guided by nerve stimulator (TOF). Fluid replacement was in the form of crystalloids, colloids and blood according to the fasting hours, duration of surgery and amount of blood loss. Monitoring of vital signs (heart rate, blood pressure, electrocardiogram tracing, oxygen saturation and end-tidal $\mathrm{CO} 2$ ) was done using Datex cardioscope.

Twenty minutes before the anticipated end of surgery, patients were randomized into two equal groups: dexmedetomidine group (group $\mathrm{D}$ ) and morphine group (group M). Group D (30 patients) received dexmedetomidine by IV infusion, initial loading dose $1 \mu \mathrm{g} / \mathrm{kg}$ given over $15 \mathrm{~min}$ at rate of $4 \mu \mathrm{g} / \mathrm{kg} / \mathrm{h}$, followed by a titrated maintenance dose $(0.4 \mu \mathrm{g} / \mathrm{kg} / \mathrm{h})$ given for 3h. Group M (30 patients) received morphine sulphate IV $(0.07 \mathrm{mg} / \mathrm{kg})$, followed by normal saline via infusion pump by the same technique like group D for blinding purposes.

At the end of surgery, residual neuromuscular blockade was antagonized by neostigimine $(0.04 \mathrm{mg} / \mathrm{kg} \mathrm{IV})$ and atropine $(0.02 \mathrm{mg} / \mathrm{kg} \mathrm{IV})$. All patients were extubated in the operative room. The time of cessation of anesthetic administration and the time of recovery from anesthesia (defined as patient's first response to spoken command) were recorded. From that, the awakening time (emergence and recovery from anesthesia) was calculated.

The patients were transferred to the post anesthesia care unit (PACU). In the PACU continuous monitoring of vital signs was done. An observer blinded to the research recorded heart rate (HR), mean arterial blood pressure (MAP), respiratory rate and oxygen saturation every $30 \mathrm{~min}$ for 3h (study period).

Postoperative morphine therapy was titrated per standard PACU criteria by a nurse blinded to the research. Postoperative pain was assessed using a 10-point visual analog scale (VAS). Patients with pain score more than 5 at any given 5-min assessment were considered to have severe pain and morphine was given via PCA pump providing $2 \mathrm{mg}$ IV bolus with a 5minute lockout. Total morphine consumption in the PACU was calculated and recorded by a member of staff blinded to the treatment. Sedation in PACU was also assessed every $30 \mathrm{~min}$ for $3 \mathrm{~h}$ using sedation score (graduated from 0-10). Postoperative nausea retching and vomiting (PONV) in the PACU were recorded. The number of patients in each group felt nauseated or had an emetic episode (single vomit or retch) or received a rescue antiemetic were calculated.

All values were expressed as mean (SD) or number (\%). Results were compared using the unpaired Student's t test and Mann-Whitney U test. Categorical variables were examined by the chi-square test and Fisher's exact test. All tests were considered significant at $\mathrm{P}<0.05$.

\section{Results}

Patient's demographics and intraoperative data were summarized in (table 1). The studied groups were similar in age, sex, weight, height and ASA physical status. The type and duration of 


\section{Khaled Taha}

surgical procedures were similar in the studied groups. No significant differences between the groups in the intraoperative doses of fentanyl, intraoperative HR, intraoperative MAP, duration of anesthesia, awakening time, $(\mathrm{P}>0.05)$.

The cardiovascular and respiratory effects of the studied drugs were shown in (tables 2-5). The results in (table 2 and 3) showed that the use of dexmedetomidine was associated with significant slowing in HR $(\mathrm{P}<0.05)$ and decrease in MAP $(\mathrm{P}<0.05)$ during the entire $\mathrm{PACU}$ recovery period.

The results in (tables 4 and 5) showed no significant differences between the studied groups in respiratory rate $(\mathrm{P}>0.05)$ or oxygen saturation $(\mathrm{P}>0.05)$ throughout the entire PACU recovery period.
The level of sedation (table 6) was similar in both groups during the PACU recovery period. No significant differences in sedation score between the group throughout the entire PACU recovery period $(\mathrm{P}>0.05)$.

The results in (table 7) showed that the mean morphine consumption in PACU in group D $(3.5 \mathrm{mg})$ was significantly lower than that in group $\mathrm{M}(10.5 \mathrm{mg})$. Patients who received dexmedetomidine required significantly less morphine to control postoperative pain during the entire PACU recovery period $(\mathrm{P}<0.05)$.

The results in (table 8) showed less incidence of PONV in the dexmedetomidine group $(\mathrm{P}<0.05)$

Table (1): Patients' demographics and operations' details. Values are expressed as mean (SD) except number (\%).

\begin{tabular}{|l|c|c|}
\hline & $\begin{array}{c}\text { Group-D } \\
(\mathrm{n}=30)\end{array}$ & $\begin{array}{c}\text { Group-M } \\
(\mathrm{n}=30)\end{array}$ \\
\hline Age $(\mathrm{yr})$ & $47(12)$ & $49(11)$ \\
Sex $(\mathrm{m} / \mathrm{f})$ & $13 / 17$ & $12 / 18$ \\
Weight $(\mathrm{Kg})$ & $69(8)$ & $68(9)$ \\
Height $(\mathrm{Cm})$ & $167(11)$ & $165(12)$ \\
Physical status (n) & & \\
ASAI & $14(47)$ & $15(50)$ \\
ASA II & $16(53)$ & $15(50)$ \\
Operation type (n) & & \\
Colostomy & $12(40)$ & $13(43)$ \\
Radical cystectomy & $7(23)$ & $6(20)$ \\
Major gynecological surgery & $9(30)$ & $8(27)$ \\
Vascular abdominal surgery & $2(7)$ & $3(10)$ \\
Intraoperative fentanyl $(\mu \mathrm{g})$ & $315(98)$ & $320(90)$ \\
Intraoperative HR (beats/min) & $67(9)$ & $66(8)$ \\
Intraoperative MAP (mm Hg) & $83(7)$ & $84(9)$ \\
Duration of surgery (min) & $202(88)$ & $229(93)$ \\
Duration of anesthesia (min) & $238(75)$ & $245(82)$ \\
Awakening time (min) & $11.5(1.7)$ & $11.8(1.5)$ \\
\hline No significant differm
\end{tabular}

\section{No significant differences between groups.}

Table (2): HR in PACU. Values are expressed as mean (SD).

\begin{tabular}{|c|c|c|}
\hline \multirow{2}{*}{ Time in PACU (min) } & \multicolumn{2}{|c|}{ HR (beats/min) } \\
\cline { 2 - 3 } & $\begin{array}{c}\text { Group-D } \\
(\mathrm{n}=30)\end{array}$ & $\begin{array}{c}\text { Group-M } \\
(\mathrm{n}=30)\end{array}$ \\
\hline 30 & $65(2)$ & $74(3)$ \\
60 & $66(1)$ & $76(2)$ \\
90 & $67(1)$ & $75(1)$ \\
120 & $64(2)$ & $75(2)$ \\
150 & $68(1)$ & $77(1)$ \\
180 & $63(3)$ & $73(2)$ \\
\hline
\end{tabular}

The use of dexmedetomidine was associated with significant slowing in HR throughout the entire PACU recovery period $(\mathbf{P}<\mathbf{0 . 0 5})$. 
Table (3): MAP in PACU. Values are expressed as mean (SD).

\begin{tabular}{|c|c|c|}
\hline \multirow{2}{*}{ Time in PACU (min) } & \multicolumn{2}{|c|}{ MAP (mm Hg) } \\
\cline { 2 - 3 } & $\begin{array}{c}\text { Group-D } \\
(\mathrm{n}=30)\end{array}$ & $\begin{array}{c}\text { Group-M } \\
(\mathrm{n}=30)\end{array}$ \\
\hline 30 & $85(6)$ & $97(4)$ \\
60 & $87(7)$ & $96(6)$ \\
90 & $84(8)$ & $95(3)$ \\
120 & $86(5)$ & $94(5)$ \\
150 & $85(2)$ & $95(8)$ \\
180 & $83(4)$ & $94(6)$ \\
\hline
\end{tabular}

The use of dexmedetomidine was associated with significant decrease in MAP throughout the entire PACU recovery period $(\mathbf{P}<0.05)$.

Table (4): Respiratory rate in PACU.Values are expressed as mean (SD).

\begin{tabular}{|c|c|c|}
\hline \multirow{2}{*}{ Time in PACU (min) } & \multicolumn{2}{|c|}{$\begin{array}{c}\text { Respiratory rate } \\
\text { (breaths/min) }\end{array}$} \\
\cline { 2 - 3 } & $\begin{array}{c}\text { Group-D } \\
(\mathrm{n}=30)\end{array}$ & $\begin{array}{c}\text { Group-M } \\
(\mathrm{n}=30)\end{array}$ \\
\hline 30 & $14(1)$ & $13(2)$ \\
60 & $13(2)$ & $13(1)$ \\
90 & $15(2)$ & $14(2)$ \\
120 & $13(1)$ & $14(1)$ \\
150 & $14(2)$ & $14(2)$ \\
180 & $13(1)$ & $14(1)$ \\
\hline
\end{tabular}

No Significant differences in respiratory rate between groups throughout the entire PACU recovery period $(\mathbf{P}>0.05)$.

Table (5): Oxygen saturation (\%) in PACU. Values are expressed as mean (SD).

\begin{tabular}{|c|c|c|}
\hline \multirow{2}{*}{ Time in PACU (min) } & \multicolumn{2}{|c|}{ O2 saturation (\%) } \\
\cline { 2 - 3 } & $\begin{array}{c}\text { Group-D } \\
\text { (n=30) }\end{array}$ & $\begin{array}{c}\text { Group-M } \\
(\mathrm{n}=30)\end{array}$ \\
\hline 30 & $96(1)$ & $97(1)$ \\
60 & $98(1)$ & $98(2)$ \\
90 & $97(2)$ & $97(1)$ \\
120 & $98(1)$ & $98(2)$ \\
150 & $97(1)$ & $98(1)$ \\
180 & $98(1)$ & $97(1)$ \\
\hline
\end{tabular}

No significant differences in $\mathrm{O} 2$ saturation between groups throughout the entire PACU recovery period $(\mathbf{P}>\mathbf{0 . 0 5})$.

Table (6): Sedation score (graduated from 0-10) in PACU ( $0=$ asleep and $10=$ wide awake). Values are expressed as mean (SD).

\begin{tabular}{|c|c|c|}
\hline \multirow{2}{*}{ Time in PACU $(\min )$} & \multicolumn{2}{|c|}{ Sedation score } \\
\cline { 2 - 3 } & $\begin{array}{c}\text { Group-D } \\
(\mathrm{n}=30)\end{array}$ & $\begin{array}{c}\text { Group-M } \\
(\mathrm{n}=30)\end{array}$ \\
\hline 30 & $5.1(0.1)$ & $5.1(0.2)$ \\
60 & $5.5(0.3)$ & $5.4(0.2)$ \\
90 & $4.9(0.2)$ & $5.2(0.1)$ \\
120 & $5.1(0.3)$ & $5.2(0.1)$ \\
150 & $5.1(0.2)$ & $5.2(0.1)$ \\
180 & $5.6(0.2)$ & $5.5(0.3)$ \\
\hline
\end{tabular}

No significant differences in sedation score between groups throughout the entire PACU recovery period $(\mathbf{P}>\mathbf{0 . 0 5})$. 
Table (7): Total morphine consumption (mg) in PACU (study period). Values are expressed as mean (SD).

\begin{tabular}{|c|c|}
\hline $\begin{array}{c}\text { Group-D } \\
(\mathrm{n}=30)\end{array}$ & $\begin{array}{c}\text { Group-M } \\
(\mathrm{n}=30)\end{array}$ \\
\hline $3.5(1.2)$ & $10.5(1.4)$ \\
\hline
\end{tabular}

Patients receiving dexmedetomidine required significantly less morphine to control postoperative pain $(\mathbf{P}<0.05)$.

Table (8): Incidence of PONV in the studied groups: number (\%) of patients felt nauseated or had an emetic episode (single vomit or retch) or received a rescue antiemetic in PACU (study period).

\begin{tabular}{|c|c|}
\hline $\begin{array}{c}\text { Group-D } \\
(\mathrm{n}=30)\end{array}$ & $\begin{array}{c}\text { Group-M } \\
(\mathrm{n}=30)\end{array}$ \\
\hline $12(40)$ & $18(60)$ \\
\hline
\end{tabular}

The incidence of PONV was significantly less in the dexmedetomidine group $(\mathrm{P}<0.05)$.

\section{Discussion}

Alpha-2 adrenoceptor agonists have several beneficial actions during the perioperative period. They decrease sympathetic tone, with attenuation of the neuroendocrine and hemodynamic responses to anesthesia and surgery ${ }^{(4-6)}$. They also reduce anesthetic and opioid requirements $^{(7,8)}$, and cause sedation and analgesia ${ }^{(9)}$. They allow psychomotor function to be preserved while letting the patient rest comfortably ${ }^{(10,11)}$. With these combination of effects, alpha-2 adrenoceptor agonists may offer benefits in the prophylaxis and adjuvant treatment of perioperative myocardial ischemia ${ }^{(12)}$. Furthermore, their roles in pain management and regional anesthesia are expanding ${ }^{(13)}$.

Several reports supported the use of dexmedetomidine as a novel drug for sedation and analgesia in the intensive care units especially for those intubated and mechanically ventilated patients ${ }^{(14-17)}$.

The present study was focused on evaluation of the efficacy of dexmedetomidine to control postoperative pain following major abdominal surgeries. The analgesic property of dexmedetomidine was assessed as a primary target. The safety and the associated hemodynamic effects of this drug were also assessed and compared to those of the standard postoperative analgesic opioid (morphine).

In this study dexmedetomidine was administered 20 minutes before the anticipated end of surgery in an attempt to attain a therapeutic analgesic level before completion of surgery ${ }^{(4)}$.

No significant differences were observed between the studied groups in the time taken to wake up from anesthesia, the time spent in the PACU. Patients who received dexmedetomidine required significantly less amounts of morphine $(\mathrm{P}<0.05)$ to achieve equivalent analgesia and reasonnable pain and sedation scores (tables 6-7). Because of its sedative and analgesic effects, there was a significant reduction in the amount of morphine given through PCA apparatus during the entire PACU recovery period. The mean morphine consumption in the dexmedetomidine group $(3.5 \mathrm{mg})$ was significantly lower than that in the morphine group (10.5mg), which meant that the total PACU morphine consumption in the dexmedetomidine treated group was decreased by $2 / 3$ to achieve reasonable and equivalent analgesia. The activation of the alpha-2 adrenoceptor located on the spinal terminals of the primary sensory neurons leading to suppression of release of the pain neurotransmitters might explain the analgesic property of dexmedetomidine ${ }^{(18-20)}$. 
Besides being an analgesic drug on its own merits, dexmedetomidine was found to have the ability to enhance in a synergistic way opioids-induced analgesia ${ }^{(21,22)}$.

The use of dexmedetomidine was associated with significant $(\mathrm{P}<0.05)$ slowing in HR (table 2) and decrease in MAP (table 3) throughout the entire PACU recovery period. Respiratory rate and oxygen saturation were maintained and not changed (tables 4-5).

The cardiovascular effects of dexmedetomidine could be part of the therapeutic goals in surgical patients at risk of adverse cardiovascular events. Indeed, activation of the sympathetic nervous system in the perioperative period increases cardiovascular morbidity and mortality in patients with ischemic or non-ischemic heart diseases. Perioperative therapy with alpha-2 adrenoceptor agonists or beta-blockers decreases both the incidence of myocardial infarction and mortality in the perioperative period $^{(12,23)}$. It was the reduction of heart rate, and not the beta-adrenergic receptor blockade per se that was beneficial in terms of improvement of cardiovascular morbiddity in the perioperative setting ${ }^{(24)}$. By slowing the HR, dexmedetomidine contributes to increase coronary blood supply to the left ventricle through prolongation of diastole and a decrease in the myocardial oxygen consumption. In addition, after load is decreased especially in high risk hypertensive patients. Therefore, dexmedetomidine could be useful adjunct to patients with cardiovascular problems providing protective pharmacological profile with moderate sympathetic depression which is quite useful in cardiac surgery and general surgery for patients with heart diseases.

PONV are accepted side-effects after major abdominal surgeries especially in patients receiving morphine PCA ${ }^{(25-28)}$. The present study revealed less incidence of PONV in the dexmedetomidine group through the entire PACU recovery period $(\mathrm{P}<0.05)$. This because the amount of morphine consumed through PCA in the dexmedetomidine group was reduced by 2/3 (table 7).

In conclusion, dexmedetomidine exhibited both analgesic and sedative properties. The associated cardiovascular protective profile and the lack of respiratory depression made it potentially extremely interesting for postoperative analgesia after major abdominal surgeries.

\section{References}

1. Khan ZP, Ferguson CN, Jones RM. Alpha-2 and imidazoline receptor agonists. Their pharmacology and therapeutic role. Anaesthesia, 1999; 54: 146-156.

2. Guo TZ, Jiang JY, Butterman AE. Dexmedetomidine injection into the locus coeruleus produces antinociception. Anesthesiology, 1997; 84: 873-881.

3. Aantaa R. Assessment of the sedative effects of dexmedetomidine, an alpha-2 adrenoceptor agonist, with analysis of saccadic eye movements. Pharmacol Toxicol, 1991; 68: 394-398.

4. Talke P, Richardson CA, Scheinin M, Fisher DM. Postoperative pharmacokinetics and sympatholytic effects of dexmedetomidine. Anesth Analg, 1997; 85: 1136-1142.

5. Talke P, Chen R, Thomas B. The hemodynamic and adrenergic effects of perioperative dexmedetomidine infusion after vascular surgery. Anesth Analg, 2000; 90: 834-839.

6. Venn RM, Bryant A, Hall G, Grounds RM. Effects of dexmedetomidine on adrenocortical function, and the cardiovascular, endocrine and inflammatory responses in post-operative patients needing sedation in the intensive care unit. $B J A$, 2001; 86: 650-656.

7. Aho M, Lehtinen AM, Erkola O, Kallio A, Korttila K. The effect of intravenously administered dexmedetomidine on perioperative hemodynamics and isoflurane requirements in patients undergoing abdominal hysterectomy. Anesthesiology, 1991; 74(6): 997-1002.

8. Scheinin B, Lindgren I, Randell T, Scheinin M. Dexmedetomidine attenuates sympathoadrenal response to tracheal intubation and reduces the need for thiopentone and perioperative fentanyl. BJA, 1992; 68: 126-131.

9. Arain SR, Ebert TJ. The efficacy, side effects, and recovery characteristics of dexmedetomidine versus propofol when used for intraoperative sedation. Anesth Analg, 2002; 95: 461-466.

10. MacDonald E, Scheinin H, Scheinin M. Behavioral and neurochemical effects of 


\section{Khaled Taha}

medetomidine: a novel veterinary sedative. Eur J. Pharmacol, 1998; 158: 119-127.

11. Hall JE, Uhrich TD, Baney JA et al. Sedative, amnestic and analgesic properties of small dose dexmedetomidine infusion. Anesth Analg, 2000; 90: 699-705.

12. Oliver MF, Goldman B, Julian DG, Holme I. Effect of alpha-2 adrenoceptor mivazerol on perioperative cardiac complications during non-cardiac surgery in patients with coronary heart disease. Anesthesiology, 1999; 91: 951-961.

13. Eisenach JC, DE Kock M, Klimscha W. Alpha-2 adrenergic agonists for regional anesthesia. Anesthesiology, 1996; 85: 9199.

14. Venn RM, Bradshaw CJ, Spencer R. Preliminary UK experience of dexmedetomidine, a novel agent for postoperative sedation in the intensive care unit. Anaesthesia, 1999; 54: 1136-1142.

15. Venn RM, Hell J, Grounds RM. Respiratory effects of dexmedetomidine in the surgical patients requiring intensive care. Critical care, 2000; 4: 302-308.

16. Venn RM, Grounds RM. Comparison between dexmedetomidine and propofol for sedation in the intensive care unit: patient and clinician perceptions. BJA, 2001; 87(5): 684-690.

17. Takrouri MS, Seraj MA, Ghanna AB, El-Dawlatly AT, et al. Dexmedetomidine in intensive care unit. The $18^{\text {th }}$ Anesthesia international Egyptian Conference, Cairo, Egypt, 2002, pp.: 73-75.

18. Sullivan AF, Kalso EA, MC quay HJ, Dickenson AH. The antinociceptive actions of dexmedetomidine on dorsal horn neuronal responses in the anesthetized rat. Eur J. Pharmacol, 1992; 215: 127-133.

19. Pertovaara A, Hamalainen MM, Kauppila A, Mecke E, Carison S.: Dissociation of the alpha-2 adrenergic antinociception from sedation following microinjection of medetomidine into the locus coeruleus in rats. Pain, 1994; 59: 207-215.

20. Buerkle H, Yaksh TL. Pharmacological evidence for different alpha-2 adrenergic receptors in mediating analgesia and sedation in the rat. BJA, 1998; 81, 208-215.

21. Ossipov MH, Harris S, Lloyd $\mathbf{P}$, Messineo E, et al.: Antinociceptive interaction between opioids and medetomidine systemic activity and spinal synergy. Anesthesiology, 1990; 73:12271235.

22. Meert TF, DE Kock M. Potentiation of the analgesic properties of fentanyl-like opioids with alpha-2 adrenoceptor agonists in rats. Anesthesiology, 1993; 81: 677-688.

23. Mangan DT, Layug EL, Wallace A, Tateo I. Effect of atenolol on mortality and cardiovascular morbidity after noncardiac surgery. Multicenter study of perioperative ischemia. N Engl J. Med., 1996; 335: 17131720.

24. Raby KE, Brull SJ, Timimi F, Akhtars. The effect of heart rate control on myocardial ischemia among high-risk patients after vascular surgery. Anesth Analg, 1999; 88: 477-482.

25. Lerman J. Surgical and patient factors involved in postoperative nausea and vomiting. BJA, 1992; 69 (Suppl): 24-32.

26. Watcha MF, White PF. Postoperative nausea and vomiting. Its etiology, treatment and prevention. Anesthesiology, 1992; 77: 162-164.

27. Watcha MF. The cost-effective management of postoperative nausea and vomiting. Anaesthesia, 2000; 92: 931-933.

28. Lee $\mathbf{Y}$, Lin YS, $\mathbf{C}$ ben $\mathbf{Y} \mathbf{H}$. The effect of dexamethasone upon patient controlled analgesia-related nausea and vomiting. Anaesthesia, 2002; 57 (7): 705-709. 


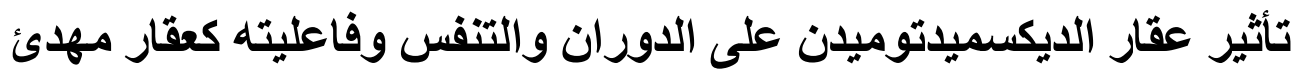

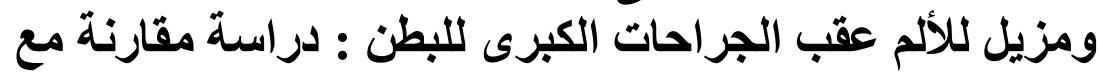

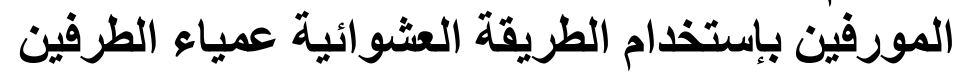

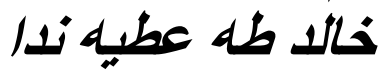

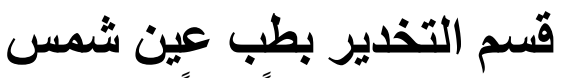

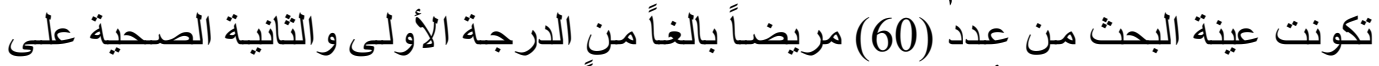

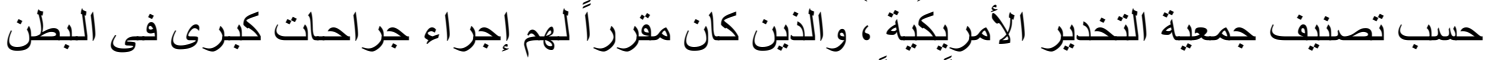

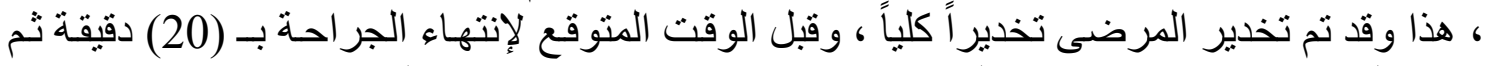

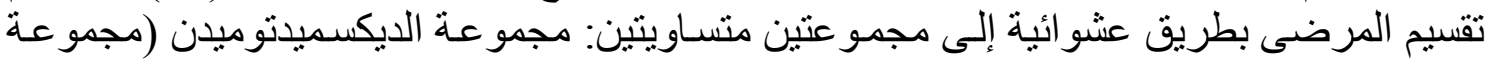

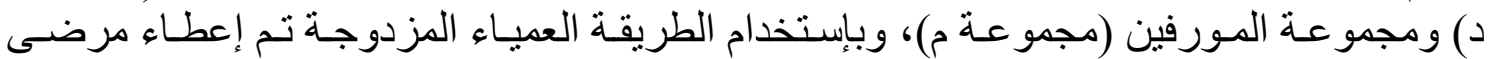

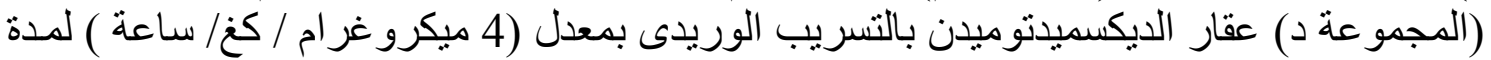

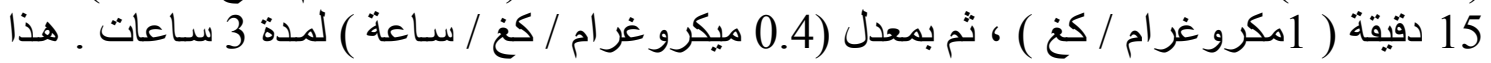

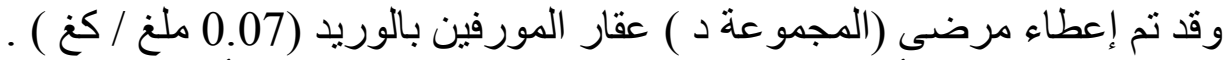

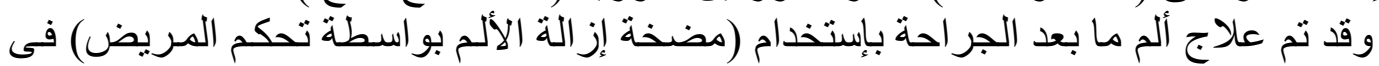

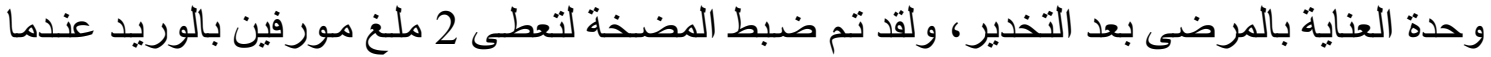

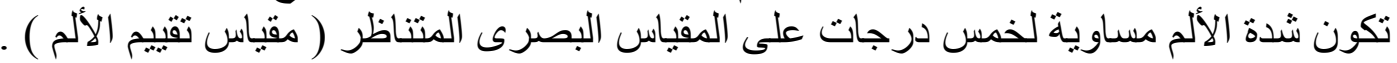

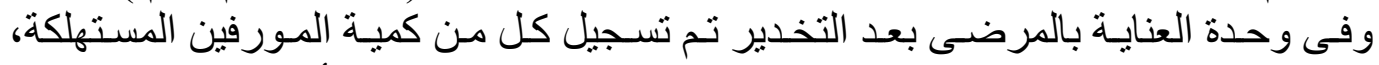

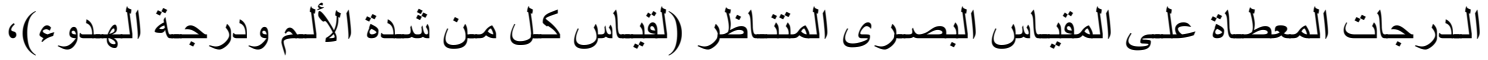

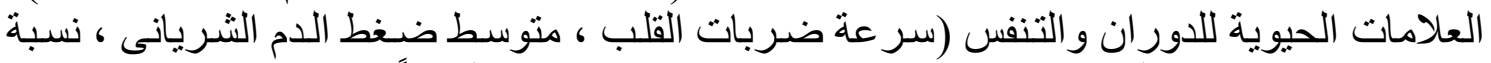

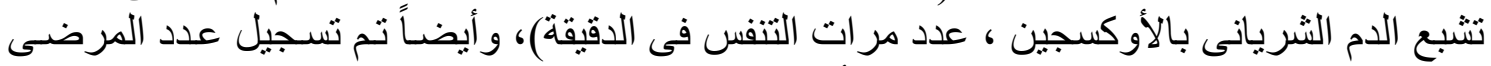

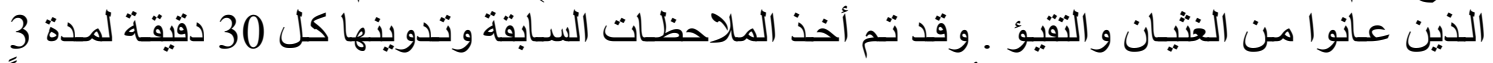
ساعات ( فترة الدر اسة ) بو اسطة أحد العاملين بوحدة العناية بعد التخدير ، و والذى كان لانئ بعلم شيئاً

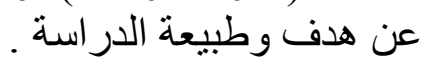

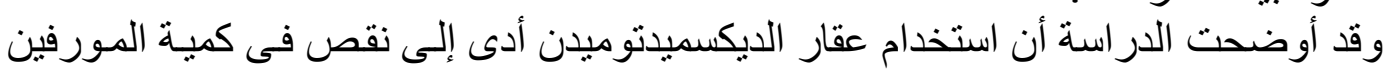

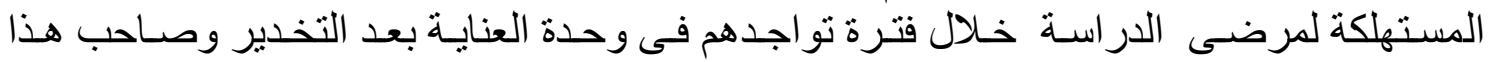

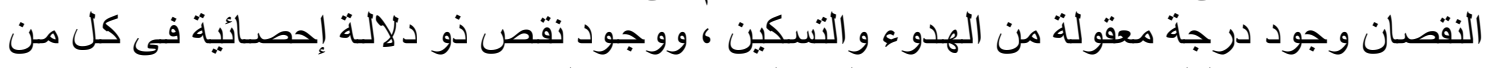

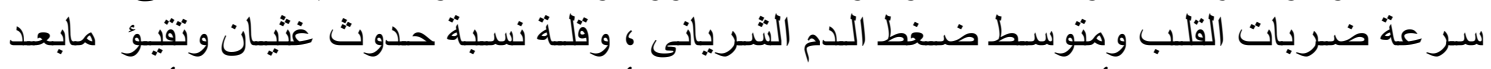

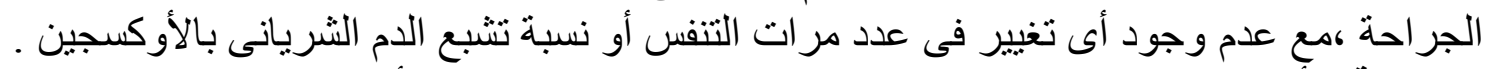

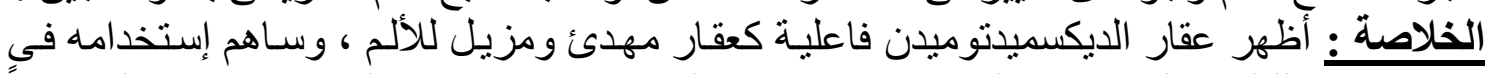

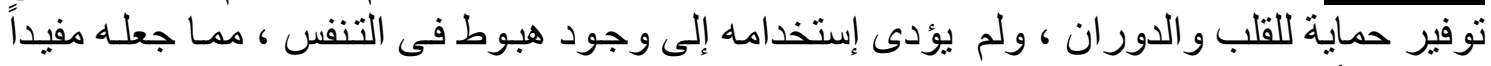
كمزيل للألم بعد العمليات الكبرى فى البطن . 